University of Wollongong

Research Online

Faculty of Social Sciences - Papers (Archive) Faculty of Arts, Social Sciences \& Humanities

2012

Critical geographies with the state: the problem of social vulnerability and the politics of engaged research

\author{
Pauline M. McGuirk \\ University of Wollongong, pmcguirk@uow.edu.au \\ Phillip O'Neill \\ Universty of Western Sydney
}

Follow this and additional works at: https://ro.uow.edu.au/sspapers

Part of the Education Commons, and the Social and Behavioral Sciences Commons

Research Online is the open access institutional repository for the University of Wollongong. For further information contact the UOW Library: research-pubs@uow.edu.au 


\title{
Critical geographies with the state: the problem of social vulnerability and the politics of engaged research
}

\begin{abstract}
State interventions to govern social vulnerability highlight the complexity of contemporary states, marked by neoliberal agenda but also by progressive interventions and the desire for effectiveness. This paper draws on collaborative research with government agencies on social vulnerability in the Hunter region to assess the desirability of undertaking critical geographies with the state. We see states as contested terrains invested with the institutional capacity to mobilise diverse political projects. We argue that critical research in partnership with states is possible, as are mobilisations of the agency of state institutions to promote progressive policy development. The paper explores how we might use engaged research to intersect with the production and circulation of texts, technologies and practices within the state apparatus to achieve desirable change. While critical research with the state involves uncertainties and compromise, with no permanent resolutions, we conclude that states must remain centred in our critical conversations and praxis. In this paper we advance the case for the critical possibilities of policy-oriented research with the state. We reflect on experiences of an engaged research project with state government agencies in the NSW Hunter Region involving the production and use of the texts and technologies as state interventions in social vulnerability. Working through the project's reflexive, collaborative methodologies and our use of critical GIS, we highlight the creation of opportunities to change how the components of social vulnerability were conceptualised, contest policymakers' view of what was "relevant", and shift framing rationalities and resultant state practices. As such the paper contributes to our knowledge of strategic research practices for pursuing critical, progressive projects with the state. Such engagement involves uncertainties and contingent compromise. Yet, as terrains of contestation wherein diverse political projects are assembled and propelled, states must remain centred in our critical conversations and in our critical praxis.
\end{abstract}

\section{Keywords}

politics, engaged, research, state, problem, social, critical, vulnerability, geographies

\section{Disciplines}

Education | Social and Behavioral Sciences

\section{Publication Details}

McGuirk, P. \& O'Neill, P. (2012). Critical geographies with the state: the problem of social vulnerability and the politics of engaged research. Antipode: a radical journal of geography, 44 (4), 1374-1394. 
Critical geographies with the state: the problem of social vulnerability and the politics of engaged research.

Pauline $M \stackrel{ }{-}$ Guirk

Phillip O'Neill

Published in Antipode

\section{ACKNOWLEDGEMENTS}

This research has been funded by Australian Research Council Linkage Project LP0776385 (“Enabling inter-agency data sharing to support the spatial analysis of social vulnerability in a transforming region") with co-funding from the NSW Department of Premier and Cabinet (Hunter) and the Regional Managers Network (Hunter). Thanks are due to all members of the research team, the research partners that participated in the research project, the Crown Solicitors of NSW, the Office of the NSW Privacy Commissioner, and the solicitors of the University of Newcastle and the University of Western Sydney. Thanks are also due to the Department of Geography at University of British Columbia and School of Geography and the Environment at University of Oxford respectively for their generosity in hosting the authors during the time this paper was written. Three anonymous referees and the editor also provided helpful, constructive comments, for which we are grateful.

\footnotetext{
Abstract

State interventions to govern social vulnerability highlight the complexity of contemporary states, marked by neoliberal agenda but also by progressive interventions and the desire for effectiveness. This paper draws on collaborative research with government agencies on social vulnerability in the Hunter region to assess the desirability of undertaking critical geographies with the state. We see
} 
states as contested terrains invested with the institutional capacity to mobilise diverse political projects. We argue that critical research in partnership with states is possible, as are mobilisations of the agency of state institutions to promote progressive policy development. The paper explores how we might use engaged research to intersect with the production and circulation of texts, technologies and practices within the state apparatus to achieve desirable change. While critical research with the state involves uncertainties and compromise, with no permanent resolutions, we conclude that states must remain centred in our critical conversations and praxis.

Keywords: Critical geographies, poststructural state, engaged research, social vulnerability 


\section{INTRODUCTION}

In recent decades, global socio-cultural, economic and political transformations have been matched by the proliferation of theoretical prisms through which we understand and construct the world. Theoretical and empirical certitudes are few and the times have invoked intense and polarising debates on what constitutes radical scholarship, what research practices are appropriate and what potentialities might be imagined. Contemporary critical geographers confront scenarios in which '... (h)eretofore straightforward assumptions about allies and foes, principled options, and dangerous strategies, have become destabilized' (Klodawsky , 2007 2845), requiring according to Castree et al $(2010,5)$ '....a much more complex definition of the enemy, political programmes and relations to state power.' Challenging questions ensue: what issues demand engagement; through what strategies and methodologies; and through affiliation with whom?

In this paper we are concerned primarily with the production of critical geographies through engagement with the state. Our paper has three key threads. First, we advance the case for the critical possibilities of policy-oriented research in partnership with the state using our experience of an engaged research project. Second, to develop the case, we engage poststructural insights on states as complex terrains of contestation in which co-evolving political projects are assembled and operationalised through networks of people, institutions, knowledges, texts, technologies and practices (Larner et al 2007). But we are alert to the enduring capacity that inheres within the institutional and regulatory condition of the state apparatus. This enables states to propel political projects which may, by turn, be neoliberalising, regressive, disciplinary, progressive, redistributive, and democratising. As such, we argue, the state cannot be fixed as an entity or as an agent of social change and must remain centred in our conversations and in our sights for critical praxis.

Third, we deal with critically-charged methodology. Enacting critical geographical research with the state demands reflexive choices about appropriate research objectives, practices, technologies and rules of engagement. Our discussion draws on our experience of working with the state to develop a 
particular engaged research approach involving critical GIS. In this venture our academic research team worked collaboratively with state partners to select, develop and apply appropriate forms of measurement, analysis and representation in a state-sponsored intervention project concerning the management of social vulnerability. Here our disposition was often nervous, sometimes anxious. Nevertheless, in this paper we make an attempt to assess the experience of partnering the state in enacting a social intervention with a view to making a claim for how this type of intervention might be seen as both progressive and productive.

Our project - the Spatial Data Analysis Project (SDAP) - is based in the Hunter region on the outer northern edge of the greater metropolitan region of Sydney. The Hunter region is experiencing significant population growth, and has a substantial incidence of socially vulnerable populations with growing demands on public sector resources. SDAP is a collaboration with the NSW Department of Premier and Cabinet (DPC) and the Regional Managers Network (RMN) which formally coordinates the region's key state human service agencies. The RMN's priority is to assemble whole-ofgovernment approaches so that its limited resources are deployed more efficiently, effectively and equitably. Based on successful similar work, our academic research team ' became involved in a project to assist agencies to better understand and track social vulnerability. This required the development of fine-grained metrics using multi-agency data that had never previously been utilised outside the institutional boundaries of individual RMN agencies-a novel process in the Australian public sector landscape. These metrics needed to be capable of two things: the determination of cross-regional priorities; and the identification of trends at an early stage. But the project had the wider objective of changing government practices around the governance of social vulnerability through the process of engaged research. As such we engaged, from a critical perspective, with the production and use of the texts and metrics, the technologies that constitute the state's interventions in social vulnerability. And we drew on an engaged research methodology, critically, to create opportunities to change how the components of social vulnerability were conceptualised, contest what was considered 'relevant' by policy-makers, and transform real government practices. 
In what follows, drawing on our experience, we reflect on the progressive potentialities of the state apparatus and our related logics of critical engagement. Our claim, in brief, is that strategic engagement with the state can produce sites from which it is possible to advance Marcuse's (2009) formulation for critical theory: to 'expose, propose and politicise'. Section 2 directly addresses the case for policy-oriented research in partnership with the state as an opportunity for critical geography. Section 3 elaborates our understanding of the state in poststructural terms, and as encompassing (still) the capacity for progressive social interventions. Section 4 suggests the critical potential of engaged research methodologies for working with the state. Sections 5 and 6 analyse our experience with SDAP and the learning it enables about strategic research practices for pursuing critical, progressive projects with the state. Finally, we reflect on the lingering and probably untreatable anxieties that inhere in pursuing critical geography through partnering with the state.

\section{RELEVANT, ENGAGED AND CRITICAL POLICY-ORIENTED RESEARCH?}

Critical geographies are concerned with the analysis of power, domination and injustice, and involve a commitment to progressive social and environmental change through an embrace of critical reflexivity and an engagement with politics. Lest this suggest ontological or epistemological commonality, for Castree (2000: 956) the label provides 'an homologous umbrella term for that plethora of antiracist, disabled, feminist, green, Marxist, postmodern, post-colonial, and queer geographies which now constitute the large, dynamic, and broad-based disciplinary Left'. The encouragement of diversity, though, comes with criticism including that critical geography has suffered from the loss of political commitment (Harvey 2006) and seduction by faddish abstractions with little social relevance (Martin 2001), and a lament for attention to capitalism's structural and material underpinnings (Smith 2005). Nonetheless, a less prescriptive, more pluralistic approach to critical geographies is now widely accepted (Blomley 2008), alongside an ongoing commitment to 'relevance' especially in work centred on the state's role in producing distributive justice (Murphy 2006). But there is also recognition of the desirability of research practices and engagements 
unconnected to the interests of the state and its policy makers (Staheli and Mitchell 2005).

Obviously, critical geography has a major role in exposing the representations, technologies and practices of power that shape non-distributive forms of justice; and there is always abstract and experimental work with latent policy relevance while not necessarily intended for direct practical use (Amin and Thrift 2007).

Pluralism aside, though, calls for a 'turn to praxis' persist in critical geography with strong encouragement of activist research as a means of effecting social and political change (Fuller and Kitchin 2004; Chatteron 2006). Clearly, direct engagements with disempowered and disadvantaged groups are central to a critical geography research agenda, as are analyses which expose unjust, inefficient and corrupt state conduct. But what about policy-oriented research in partnership with the state? Is such work inevitably atheoretical, constrained to convention and wanting for ideology (see Pain 2006); and, perhaps, tainted, rendered mundane or even corrupted by the inclinations of a capitalist state (Bell 2007). Within the critical geographies debates, then, we see the position of policy-oriented work with the state as particularly fraught.

Not surprisingly, we make no claim that policy-oriented work or engagements with policy-makers are privileged routes to critically relevant contributions. Yet, we insist that policy-oriented work with the state remains a potentially effective route to critical praxis, without the pre-condition of accepting an acritical, 'clientist' relationship (Peck 1999, Pain 2006). In fact, we see the need to develop collaborative research practices capable of interrogating state policy as an ongoing challenge for critical research. We suggest, though, that this requires us to position the state differently in critical praxis to how it has often been constructed in the critical geographies and policy debates, both as an actor - potentially one overwhelmed by neoliberalism and stripped of the potential for progressive change - and as a potential research partner - potentially one ridden with political cynicism and short-term pragmatism. 


\section{3. (POSTSTRUCTURAL) STATES and CRITICAL POLICY-ORIENTED RESEARCH}

Poststructural theorisations suggest the impossibility of an essentialist or generalist state theory and argue for theorisations of states as peopled and dispersed, and as multiscalar, relational and assembled networks (Ferguson 2009, Painter 2006). Poststructural states are conceived not as preexisting entities but as an effect of processes of discursive and practical production and spatial operationalisation (Kuss and Agnew 2008). While they can appear as actors with a more-thanprovisional identity and coherency, such subjectivity belies their existence as fields of multi-vocal and multi-scalar, cross-cutting and conflicting interests (Clark and Dear 1984, Robertson 2010). For all this, state power-as a dispersed, fragmented and fractured event-is no less formidable (see Whitehead 2008, 416).

So we are comfortable with poststructural state theory as 'weak' theory in which states are recognised as resolutely hybrid and multilayered, resistant to a common, singular rationality, driven by diverse ideologies, and holding on to multiple political projects and motivations mobilised simultaneously. Central to our argument in this paper is that such a view of the state means that aspirations, technologies and practices identifiable as neoliberal and as social democratic, disciplinary and progressive, can be embedded together in diverse programs and at different scales across state operations. We see states as cross-cut with intense fractures and conflicts expressed across scales, agencies and actors, as multiple strategies, texts and technologies jostle in the performance of administration and governance. In this complexity, governance capacity itself emerges through experimentation that might be as prone to failure, inefficiency and unintended consequences as it is to the achievement of specific political objectives. States are always in play, then, but are subject to reconstruction by the changing discourses, technologies and practices of governing.

This view of the state as varied networks of governance programs involving numerous sites and scales does not lessen the presence, materiality and capacity of the 'real' state institutions which 
comprise 'the state apparatus' (see Clark 1992). While being relationally composed, state institutions have enduring institutional and regulatory forms and established mechanisms and technologies for their various projects. And these projects may well be contradictory in nature, arising both from the need to secure accumulation outcomes for capital (thereby entrenching inequalities) and from the desire to preserve public social services and advance progressive social interventions (thereby contesting inequalities). Indeed, for Offe $(1984 ; 1985)$, state institutions are sites defined by the resolution of contests arising from these contradictory impulses. We would add that these contests are invariably played out in contexts of ongoing fiscal insufficiency and public sector obstinacy in addressing internal inefficiencies and purposelessness (see O'Neill and Moore 2005).

So, like with any institution, state institutional capacity precipitates from its repeated practices, and the logics, rules, norms, technologies and waste that underpin them (see Gibson-Graham and O'Neill, 2001). But because this capacity arises in a field of contestation, it can never be ascribed to a singular rationality, harnessed to a single political project, or controlled by central direction, neoliberalised or otherwise (see Peck 2010, Robertson 2010). Indeed, by positing a specific resolution to sets of claims, state action is always contested by unsatisfied claims. Nothing is ever neatly resolved.

Notwithstanding neoliberalism's reworking of states' operations, then, state capacity for progressive social and redistributive interventions remains; and the practices, technologies and texts which mobilise progressive interventions are always available to be amplified. Thus states, and particularly the resources and agency of their institutions, should remain centred in our critical conversations and, more challengingly, in our critical praxis. Detached observation, however important, is insufficient. The question for critical geographies is how - rather than whether - we can intersect with the production of practices, technologies and texts through which the capacity for progressive interventions can be enhanced and operationalised.

\section{METHODOLOGIES AND TECHNIQUES OF ENGAGEMENT FOR PARTNERING THE STATE}


Enacting critical geographies with the state demands reflexive choices about appropriate research practices and methodologies. The methodologies need to work-as Marcuse (2009) suggests - to 'expose, propose and politicise' state practices and their impacts, but also to work with the institutional capacities of the state to mobilise progressive and productive interventions. Engaged, collaborative methodologies that adopt the methodological and epistemological aspirations of participatory action research (PAR) present productive possibilities here. While PAR is often conceived as co-researching with grass-roots organisations (Klodawsky 2007), the parallels for researching with the state lie in recognising the knowledge of state agencies as practitioners and, from a critical perspective, involving them in configuration of the research questions and the processes of investigation and analysis so as to enable and constitute new practices (Demerrit 2005). Reflective, critical academic researchers co-researching with the state, as activists and enablers, generate opportunities for shaping the way a given policy issue is framed and understood, for translating the questions then posed of policy-oriented research, for intersecting with the texts and technologies through which policy interventions are practiced to align them the ethics, norms and aspirations of a critical stance (see Healey 2004, Massey 2001). Inevitably, though, co-researching with the state locates academic researchers within a particular context of power relations and framing rationalities and it demands working within diverse frames of reference, negotiating institutional insecurities and conflicting demands. The engaged research paradigm, then, requires continual negotiation driven by self-conscious reflection from critical ethical and normative stances. And while this might create anxious moments, it is a paradigm far removed from one of policyoriented research where 'answers' are given to policy questions posed by government.

As we elaborate below, we have worked collaboratively with state agencies to establish an engaged research framework where, as a technique of engagement, we intersected consciously with the production of the texts and technologies through which social vulnerability was being conceived, tracked and responded to by state agencies. Working with critical GIS multiple: to critique the concept of social vulnerability and the nature and construction of habitually- 
used indicators; to create new knowledge about the social dynamics and vulnerabilities of neighbourhoods through the development of new fine-grained indicators ${ }^{\mathrm{iii}}$; to enhance agencies' critical GIS skills and understandings of socio-spatial processes; to apply GIS outputs in ways that give authority to local practitioner knowledge; and to contribute towards efficient whole-of-government modes of working to address the distribution and incidence of social vulnerability. In the sections that follow we elaborate and reflect on strategies mobilised to advance our project and address the challenges encountered; and we return to the sometimes fraught politics of doing critical geographies with the contemporary state.

\section{ENGAGING CRITICAL POLICY-ORIENTED RESEARCH: THE SPATIAL DATA ANALYSIS PROJECT}

We have been involved in a prolonged collaboration with DPC and the Hunter region's RMN which brings together the key NSW government human services agencies. The SDAP project arises from this history of activities between the academic team and NSW state government service agencies (figure 1), funded primarily by the Australian Research Council with co-funding from DPC. SDAP focussed on collaborating with state government agencies to develop soft and hard technologies to enable the production of fine-scale metrics of social vulnerability based on cross-agency data. With a related series of maps, graphs and summary reports, the metrics enable close tracking of the social character of the Hunter's varied communities. The outcomes of the research are being used by RMN to advance a whole-of-government approach to prioritising and planning human services provision across the region. The aspiration is for betterments in social equity and well-being through early intervention programs-using new powers and resources arising from cross-agency cooperation-in those neighbourhoods identified as having concentrations of social vulnerability.

The research involved establishment of a management framework involving the RMN human service agencies and DPC within a SDAP reference committee. Together we devised a suite of protocols based around a transferable memorandum of agreement to govern data-sharing processes (figure 1). ${ }^{\text {iv }}$ The MoA prescribes every aspect of data handling from data release, processing and analysis, to 
storage, access and retrieval, ownership, dissemination and, ultimately, data disposal; and it lays out the responsibilities of participating agencies and of the research team.

Guided by the MoA, the academic research team together with the participating agencies ${ }^{v}$ assessed the available data and explored various ways it could be processed to build useful spatial understandings of social vulnerability. This process of discussion and negotiation took place over many months, during which time the team worked through a preliminary GIS analysis of social vulnerability based on an indicator devised from fine-scaled census data, that could be used in composite form or disaggregated into its constituent elements. The GIS analysis allowed us to demonstrate the kinds of metrics, mapping and graphical representations that could be produced from shared data, and discuss their interpretation in a series of RMC and practitioner workshops. Outputs here informed the RMN's annual whole-of-government planning and the development of spatially targeted integrated service delivery programs over the following years. Then, as agency data was (slowly) made available to us, the team developed a range of special purpose metrics, again using GIS, to map changing spatial patterns and to expose differences between census-based and agency-based metrics. Another round of interpretive workshops with the agencies and the reference committee followed. The full suite of enhanced outputs were used again to inform the RMN's annual planning process and will inform ongoing service planning and program delivery in the region.

\section{INSERT FIGURE 1 HERE}

Figure 1: Timeline of project collaboration with NSW state institutions

As critical geographers, then, with both critical and normative concerns in the frame, we have been working to build understandings, technologies and practices that steer public service resources in ways that underwrite material well-being and progressive redistributions. But we have been conscious too that these are not straightforward tasks (see Bell 2007, Beaumont et al 2005). As much as they involve technical matters, they also involve negotiation and navigation of the possibilities and 
conflicting demands of engaging with the state. Success is not assured, and the process involves exposure to the prospects of compromise, trade-off, incompleteness and outright failure. We explore our research practices, our achievements and the discomforts they required us to negotiate in the following sections.

\section{PRACTICES FOR CRITICAL GEOGRAPHIES WITH THE STATE}

In this section we use our experience of SDAP to reflect on two research practices we see as highly productive for enacting critical research with the state:

- collaborative research, and

- the strategic development and deployment of texts and technologies to enhance social intervention practices.

\subsection{Co-constituting research}

SDAP was designed to be open-ended rather than a response to a pre-specified 'problem' (see Healey 2008). So we were able to avoid a purely instrumental conception of our task. Rather, we encouraged the research team and our partners to investigate the meaning of social vulnerability in the Hunter and generate new processes with new data to interrogate its spatial patterning. Rather than simply map spatial variation using an imported definition, we were concerned to deconstruct 'the problem'. Within our engaged, collaborative research framework, negotiations around data selection and indicator development brought the team together with state agencies in reference committee meetings, individual agency meetings and group workshops with agency practitioners. These meetings interrogated the diverse meanings and dynamics of social vulnerability, its particular complexion in the Hunter, and the understandings informing existing state practices. We explored the crudeness of common indicators, identified the resultant knowledge gaps and their effects, and considered how fine-scale observations could build connections between particular spatial events registered at a fine-scale and broader social, economic and political processes, beyond populist 'failed people in failing places' interpretations. We weighed-up what might constitute 'evidence' and 
investigated the character of data available across the agencies that might capture social vulnerability's diverse dimensions and could be made available for quantitative modelling. Then, in the development of fine-scaled indicators, we assessed the sensitivities of various agency data sets and deliberated on the effects of their inclusion and on the likely effects of data gaps. And we debated the forms of whole-of-government and early intervention that might be made possible. Both our and agencies' understandings of state agency data, its powers, partialities and potentialities, expanded.

In the process, while we could not escape our positioning with a set of power relations and framing rationalities, we aimed to expose some of the problems in the simplifications produced when 'seeing like a state' (Scott 1998) and maintain a critical sensibility to guard against 'serving the needs of the state' in any straightforwardly clientist fashion. From this position, one which we contrast to that of a research contractor, state actors across the participating agencies became our co-researchers ${ }^{\mathrm{vi}}$. We attempted to build agencies' understanding of the specificity of social vulnerability in the Hunter's spatio-temporal context into the indices and thereafter into the policy process. This was a hybrid project in so many respects, and consciously so. Devising and realising the research parameters, then, was not an 'us then them' iterative process but became relational, dialogic and interactive, moving between our systematised knowledge and the practical knowledge of the agencies; and between ideas, governmental processes and policy (Healey 2008). We maintained this approach as a conscious and performative element of our research practice, resisting the construction of a flow of innovation, evidence or enlightenment from a distinctive academic 'us' to a distinctive policy-making 'them' (see Demerrit 2005), and resisting any 'line-drawing' between 'us' as critical researchers external to the state, yet operating 'behind enemy lines' (Hanson-Thiem 2010), and 'them' as state operatives.

As we expand below, framing rationalities and resultant practices were at least partially rewired by adopting some of the methodological and epistemological aspirations of PAR and by the acts of 
exposing, proposing and politicising engrained in the collaborative process outlined above. Certainly, building collaborative relationships was just as important in our research context as in other kinds of PAR, and the strength of the relationships we built in co-constituting the research was critical to achieving this rewiring. Mirroring Routledge's (2004) observations of working with struggling activist groups, we had to be conscious of the social and political context of the SDAP research and take care in contests over agenda and priorities. We needed to know our terrain as well as the cultural, economic and political terrain of our state actors - in structural, institutional and personal senses (see Moss 2004). This was necessary to build the affinities and technical processes that could contribute to the sorts of changing practices around equitable, effective and efficient public service provision that we imagined to be possible. We needed to be conscious of the competing agenda that operate across and between state institutions ${ }^{\mathrm{vii}}$ and how these might demand different responses from us at different moments, and we needed to be reflexive about how we might respond in ways that were consistent with the ethics and norms-and constrained biases-we brought to the project as critical geographers.

Three instances, each reflective of the state as a terrain of contestation, can illustrate how productive critical research achievements unfolded. The Hunter's human services RMN undertakes annual planning as part of cross-agency competition for funding within a wider whole-of-government context. Here the physical infrastructure agencies have persuasive cases for funding priority in light of the Hunter's ongoing population growth. In order to maintain SDAP's action agenda, it was clear that even while the team was collaborating on conceptual and methodological aspects of the project, there was a need to demonstrate the practical promise of the project, and the agencies were keen to secure hard evidence of the region's social needs in the form of metrics, mapping outputs and illustrative texts. So using data from the national census we developed a first cut of indicators and spatial analysis which the agencies used successfully in their claim for funding. Fortuitously, the intellectual fix we were working towards was propelled by a political fix within the contested terrain of state prioritisation and budgeting processes, a pragmatism that helped the project build 
momentum and legitimacy, and resisted it being compromised (see Healey 2008). But our somewhat acclaimed performance at this early planning meeting not only cemented positive relationships with our co-researchers, it also secured a return invitation to the following year's event as one of a small number of key presentations seen as foundational to the determination of priorities across the region. Being able to so embed the texts and technologies of the research was a significant achievement for the project, and the competitive value earned for the research outputs helped secure their places as core inputs in developing the social intervention programs of the participating agencies.

At other times, SDAP outputs were needed to help counter central state directives that jarred with regional priorities. In one instance, agencies were called on to focus resources on a particular locality that had been identified as severely disadvantaged in a quantitative study that had received extensive national media attention. This pressure was despite local practitioners' judgment that a more nuanced understanding showed that other localities were in greater need. The RMN was able to draw from SDAP analysis, backed by the weight of the team's academic membership, to strengthen the RMN's response and to buttress arguments for a resources distribution in favour of the other localities. Enabled by the project's research process, an expanded conception of social vulnerability, interagency collaboration, and the enriched outputs these produced, the RMN used the project's evidence to contradict and interrupt a state trajectory; an outcome which we note departs strongly from Stevens' $(2011,252)$ claim that policy-makers habitually use evidence 'to tell stories that were likely to be accepted within a thought-world that favoured certainty over accuracy and action over contradiction'. The RMN drew on SDAP outputs to attach authority to local practitioner knowledge, to expand what was thought of as relevant, and to disrupt a wider state narrative.

In another instance, prior to an annual RMN planning meeting, we were asked to present a list of the most socially vulnerable localities in the Hunter. DPC sought this list to propel the social agencies' 
case to target integrated service delivery in particular localities in the face, again, of resource demands from the physical infrastructure agencies. This was a moment when we needed to meet our partner's needs without compromising our commitment to resist crude characterisation of communities using summary indicators and ranks. In discussion with DPC, drawing on the strength of our collaborative relations and working with agencies' familiarity with the logics of the indicators built through the engaged research practices, we were able to reposition the indicators as diagnostic tools, rather than ranking devices. Using the example of a locality with high and rising scores on a range of indicators, we were able to demonstrate that using indicators diagnostically revealed how thus locality's scores were driven by its high concentration of aged persons reflected in, for example, low participation in the labour force and lower levels of educational attainment. The appropriate policy response in this case would be to ensure the area received improved aged-care services even though their delivery would not change the locality's performance scores or regional ranksomething that practitioners accustomed to performing to managerial audits may instinctively seek - but this response would produce a more equitable and effective deployment of program resources. Following these discussions, we were able to embed this critical reflexivity, nuanced understanding and diagnostic application of the practice of GIS. We produced a detailed yet accessible report-including metrics, maps and interpretive text-which worked through the varied composition and context of vulnerability in struggling localities across the region. DPC then used the report alongside practitioner knowledge of localities and of knowledge of programs and interventions already in place, to come up with a case for prioritising whole-of-government interventions and resources in different, more effective ways.

These examples illuminate both the process of collaborative research with state agencies and its critical achievements in terms of re-wiring rationales and reworking practices. The process demands awareness that achievements can only occur within the contested terrains in which agencies operate and that they involve intersections with porous state institutions interested in new forms of practice on one hand yet are limited by path-dependency on the other hand (see Le Heron 2007). It is 
acknowledged that our process of engagement and relationship building was often not smooth. It had to work encouragingly with agency norms and habits resistant to new, not yet proven practices in the face of competing priorities, stretched resources and energies, turf-protection among agencies, and the inevitable inefficiencies of multi-level bureaucratic organisations. Yet, the strength of our relationships enabled us to enact processes that threw up opportunities to change how issues were conceptualised, re-order what was considered relevant by policy-makers, and begin to shift rationales and transform real government practices.

\subsection{Strategic development and deployment of technologies and texts}

Producing critical geographies requires balancing the co-construction of space and knowledge with the insistent materiality of the world and its social processes which produce enduring patterns of inequity (Massey 2001, 10). Aspiring to make critical interventions demands that we find ways to pitch our knowledge within this nexus. In our case, we were aiming to mobilise new knowledge, texts and technologies to inform and enhance the practices of progressive social intervention. Our discussion here is about our use of GIS to build fine-grained metrics of social vulnerability. On the one hand, as critical geographers we are conscious of the poststructuralist critique of GIS and an unproblematic adoption of 'Cartesian rationality, Euclidean spatial ontologies, and the often norming fixity inherent in cartographic representation' (Brown and Knopp 2008, 40). This consciousness tells us that GIS makes realities as much as it represents them: by naming, coding, and fixing the identities and imaginaries of places and people, all from an imagined politically-neutral knowledge creation position (Ramsey 2009). On the other hand, our own work-history tells us that quantitative spatial analysis has an enormous cachet among policy makers (see Poovey 1998), creating an optimism for a 'critical GIS' approach that can deploy spatial science within critical social theory without the inevitability of positivism, essentialism and reinforcement of power geometries through a conservative politics (Kwan 2009). So we align our project with post-positivist quantitative research, premised on the notion that quantitative methods, including GIS, can be viewed in a politicised way: first, by acknowledging that they are products of social, cultural, political, and institutional context; 
and, second, that they are polyvalent, able to be used carefully within diverse schools of thought and rationalities to different effect (Wyly 2009).

Our approach was to use a fairly standard GIS analysis alongside other plain statistical methods as political devices to create points of commonality between us and the interests of a fragmented but porous state. We also mobilised GIS as engineering devices, first, to bring previously unavailable state agency data into a common pool; and, second, as is its strength, to act as a prism to explore metrics and representations to enable new ways and scales of seeing communities and neighbourhoods that might reposition them as objects of social intervention (see St Martin 2009). As we produced the project's GIS outputs, our regular workshops with participating agencies provided opportunities for new learning across the agencies about critical interpretations of data, data representation, and the ambiguities of evidence. The workshops also provided key moments in which we could dislodge the interpretation of indicators as reflections of an unproblematised social reality, and demonstrate indicators' role as partial, diagnostic tools needing to be interpreted through practitioner knowledge from an array of agencies to feed the development of more sensitised programs and interventions. One proud moment that captured these multiple purposes occurred when a public servant attached to the project faced an aggressive question during a presentation on the project to head office officials. An officer asked whether the GIS analysis simply confirmed that the widely accepted view that concentrations of social housing were the prime reasons for concentrations of vulnerable households. Yes, our partner replied, before elaborating by going on to explain that because of the way the analysis is assembled she and her team could ask: Who is represented in the concentration? What circumstances were contributing to their needs? Why weren't they being satisfied? And how might local practitioner knowledges be better used to help answer these questions? So while the GIS analysis gave power and legitimacy to our partner in her response, and enabled a debilitating stereotype to be closed down, it also opened the conversation to broader conceptual questions and for a different politics of intervention to be attempted. 
By recognising that the state always has latent power, our project's texts and technologies were all the more powerful for being based on data legitimated by the state; "statistexts" if you like (Kobayashi 1993). In this understanding we probably lagged our partners' sensitivity to the circulatory power of numbers within the state apparatus. We observed early on how staff from amongst our collaborating agencies experience the political and institutional weight of indicators on an hourly basis and that they saw data as explicitly politicised media capable of powerful representation and distortion. So our partners had sophisticated understanding of the situatedness of knowledge production and a shared cynicism for the notion of objective social worlds identifiable by acts of research. To be sure, our work required degrees of abstraction, categorisations derived from particular lens of observation, the fixing of concepts and objects and their dimensions and boundaries, a call on a priori causal theory and, inevitably, reductionism and generalisation. But the indices were also developed through critical reflexivity, as we have outlined above. In an iterative data selection process with the agencies, we were careful to include variables to represent complexity and not yield to a statistical preference for simple $x-y$ relationships (see Wyly 2009). We were determined to include a variety of variables around social and subsidized housing so as to enable a complex picture to emerge; drilling down to distinguish, for example, concentrations of single-occupant older tenants, low-income students, poor households in rural towns, or camping grounds with children in mobile homes. We preferred variables that showed performance (like income and illness) and outcomes (like educational attainment and life expectancy) rather than characterisations (like Indigenous ancestry and family status) and thus invited action rather than resignation as the consequence of our partnered work. We were pleased that our agencies were quick to deconstruct the indices and use them contextually; for example by overlaying indices with agency data on service availability, and qualifying quantitative knowledge with localised practitioner knowledge, so as to fine tune existing neighbourhood programs.

The project's metrics and its graphical, cartographic and written texts enabled progressive, strategic 
understandings that we and the agencies recognise as partial and situated, yet with a capacity to drive particular state practices. To paraphrase Wyly $(2009,316)$, we generated an opportunity to construct certain kinds of facts and attempted to get 'certain things done'; such as enhancing the ability of agencies to mobilise spatial statistics and maps for progressive purposes and, potentially, counter regressive political agenda within a state field congested by contests over the distribution of always insufficient resources. In a kind of 'critical strategic positivism' (see Wyly 2009), the project aimed to mobilise the legitimacy afforded to GIS-generated texts to structure political arguments that could successfully be sustained (Elwood and Leitner 2003).

Yet claims about impact are always difficult. There is the issue of attributing a positive outcome to a specific action. Good results are always overdetermined. Timeframes are also important in judging the durability of change, especially when an intervention plays out in a slow-moving bureaucratic environment on one hand, and fast-response political frame on the other (Sabatier and JenkinsSmith 1993). In this respect, our timing was favourable since it coincided with a whole-ofgovernment urge across the NSW state apparatus, meaning the acts of data sharing together with the use of GIS functioned as a boundary-object across agencies, and so received support from most quarters. Project success also came from having genuine respect for the work and knowledge of field practitioners. These personnel saw the project's technologies and information as genuinely complementary rather than displacing, and so acted to facilitate the project's positive outcomes and its wider application. Finally, there was the compelling nature of the project's findings which were invariably interesting. The findings became popular evidence within agencies and we found stories about the findings and the technologies circulating across the agencies and into other regions, where there are now discussions about new ventures.

\section{LINGERING ANXIETIES AND UNCERTAINTIES}

Staheli and Mitchell $(2005,370)$ say '(research) is a struggle for ideas. Yet researchers are not guaranteed of winning that struggle or even necessarily guaranteed of being able to control the 
conditions under which ideas are produced'. Given the contradictory and contested terrain of the state and the diverse priorities and agenda that circulate through it, any engaged research with the state is vulnerable to uncomfortable compromise, incompleteness or outright failure. As such, its politics will be filled with anxieties and uncertainties. This particular research has presented us with three lingering anxieties and uncertainties worthy of mention.

The first relates to the potential for unintended use of the project outcomes. Our work may be hijacked, used selectively, re-described and put to work in ways beyond our control (Beaumont et al 2005). If, as Ward $(2005,316)$ puts it, 'findings' can have lives of their own' and if maps (and, we would add, texts and metrics) are ontogenic - that is, their meanings unfold as they are put to work in practice (Kitchin and Dodge 2007) - then unknown risks are always inherent. While risk exists in any collaboration, it seems to have elevated presence in collaborations with state institutions where there are latent capacities to mobilise power and enact all sorts of interventions. We cannot guarantee that the critical perspective we nurtured during the research will be reproduced when research outputs are put to work (see Ramsey 2009). There is always the possibility these outputs will become isolated from the social, institutional and political contexts of the project we worked on and, perhaps, applied as 'policy-based evidence' within community or institutional audits called-for by a neoliberalised state (Stevens 2011). And there is the risk that the 'object view of the world'-the realism and norming effects embedded in maps and metrics-might be asserted in such other deployments of the work (see Brown and Knopp 2008).

Important to our strategy for maintaining the norms of critical geographies, then, has been adopting collaborative research practices with the state agencies: integrating localised practitioner knowledge into the project parameters; developing and deploying research outputs in learning partnerships; denaturalising and politicising the production of texts and metrics; and embedding critical reflexivity into the practice of GIS. While we cannot control the lives of the research outcomes as they circulate through the state, we have developed them from a critical stance and given them critical position 
even as they take on their own trajectories.

A second, related, anxiety involves our role in rendering GIS representations of reality for the state and the related risk of contributing to the problematic simplifications that come from 'seeing like a state' (Scott 1998). Here our strategy has involved critical GIS: carefully, modestly and collaboratively producing maps, graphics and metrics, and accompanying texts to support progressive state social interventions. We think about these as contributing to what Ferguson (2009) calls the progressive arts of governing in which, by prising apart technique and rationality, it is possible to identify and mobilise an affinity between some techniques we might commonly associate with neoliberalism (e.g. quantitative metrics, spatial orderings) and certain forms of progressive politics. Governmental devices and even modes of reasoning designed and commonly used for one purpose, can be reappropriated, repurposed and recombined to other ends, to other political projects and social norms. As with our first point above, however, this is an uncertain venture.

A third anxiety relates to the project's evolution, in part, from the pressures of the neoliberalised university and its desires to demonstrate regional engagement, to capture-like the aspiration of its public sector cousin-appropriate instrumental value and credentials for relevance; and, of course, to generate external income. We were well positioned in the Australian trend to evidence-based policy making (Banks 2009). This created a niche we could exploit. And we were, no doubt, also attractive to cash-strapped state institutions because we could leverage research funds from the Australian Research Council (see Demerrit 2005). There are risks this might translate into enrolling us in a clientist or subservient relationship with the state. But this is not inevitable. In working through an engaged research paradigm rather than of one where 'answers' are given to policy questions posed by government, it is possible to work in a more experimental, open and critical mode that can shift the questions posed, the understandings made and practices adopted. If we accept that knowledge production and change in the world are interconnected (Massey 2001), then there is no reason collaboration with the state cannot aspire to produce critical geographies. But, of 
course, their realisation is contingent and path-dependent.

These anxieties - and there are others-result from the series of 'messy compromises' (Peck 2000, 257) of policy-oriented research which can only ever be negotiated in context. In a field of uncertainty, the certainty of compromise does, however, ensure that collaborative, critical research demands self-consciousness about the normative commitments with which we approach the research; in this case, with commitments to equity, justice, and freedom from domination. But these normative principles have meaning primarily in their relation to actual cases, to the analysis of actual situations and experiences in specific contexts (Olson and Sayer 2010). They do not require common means for their achievement; rather they resist commonality.

\section{CONCLUSION}

Critical geography has been said to have a tradition of being 'better at mapping current dystopias than mapping utopic alternatives' (Blomley 2007, 56) and inclined towards 'denunciatory analyses that repeatedly come to the same conclusions about the position of the powerless and the oppressed' (Ferguson 2009, 166). Of course, many critical geographies have moved beyond these characterisations through diverse forms of critical praxis. From our perspective, such praxis cannot ignore engagement with states. States are terrains of contradiction and contestation, invested with intense institutional capacity to mobilise and propel diverse political projects (Larner et al 2007, O'Neill and Moore 2005).

The colonisation of the state by neoliberal policy forms and principles, and the mobilisation of particular texts, technologies and practices to enact these, must be recognised. But by equal measure we must recognise the possibility of mobilising alternative texts, technologies and practices towards progressive ends through the agency of state institutions. Thus, we argue that states must remain centred in our conversations and our praxis, rather than being sectioned out as systemically tainted or as overwhelmed by unpalatable political rationalities. As a contested terrain, progressive 
potentialities emerge naturally within the state apparatus.

Progressive potentiaities also emerge as the state changes, and there is growing evidence of the state's propensity to forge a different type of engagement with society. Giddens, for instance (e.g. $2006,2007 a, 2007 b)$, makes claims for the arrival of a new political agenda focussed on the dramatic social transformations and polarisations of prosperity in knowledge-based, services economies. He identifies a new European state intervention model where there is a shift away from income insurance and general state support towards interventions designed to inculcate successful personal risk management behaviours with social disadvantage best alleviated through life skills development and management programs delivered by the state apparatus through a package of sanctions and incentives. Clearly there is a analytical task in plotting and interpreting such changes. But there is also the opportunity to engage, contest and alter the course of these changes by actions within.

In terms of practices for pursuing critical engagement, then, we have highlighted collaboration and the strategic development and deployment of texts and technologies. These are means whereby we can position ourselves as critical geographers in the formulation and operationalisation of progressive state interventions. Such research engagement is not confined to producing outcomes aimed solely at enhancing a narrowed list of modest state goals but, in line with critical theory, it enables exploration of the production of state-based knowledge, texts and metrics, including how these inform and enlarge state practices and the ends to which they are put ${ }^{\text {viii }}$. Importantly, they can involve the instillation of efficient and effective practices within state institutions so that progressive objectives are more often attained. We have an ongoing concern that only neoliberalist accounts of the state seem to worry publicly about state efficiency and effectiveness and support technologies for their advancement. As we argue elsewhere, the pursuit of efficiency and effectiveness within the state apparatus does not have to be a neoliberalist act, these having been the objectives of reformers throughout history, be they of the right or the left. Most notably in an Australian context, making efficiency and effectiveness up-front concerns of state agencies was seen by iconic reformer 
H.G. "Nugget" Coombs as essential to the operation of a public service committed to equitable outcomes for itself and for society at large (see O'Neill and Moore 2005).

Finally, the politics of critical research with the state are always uncertain, however well intentioned. The uncertain terrain of engagement demands that we navigate complex political situations and inevitably accept pragmatic, contingent compromise (see Woods et al forthcoming). These demand critical reflection and that we remain clear-eyed about what is possible in any given engagement. The SDAP, for example, was a moment of experimentation that could point to the shifts in governance practices, technologies and texts needed to enact more responsive and equitable ways of governing communities threatened with social vulnerability (see Healey 2004). To take hold, these practices will need to survive the ongoing contestations that define state institutions and produce embedded performances of governance. Nothing is guaranteed. Despite such uncertainties, critical research with the state cannot be discounted as a space for the production of critical geographies. 


\section{REFERENCES}

Amin A and Thrift N (2007) On being political. Transactions of the Institute of British Geography 32: $112-115$

Banks G (2009) Challenges of Evidence-Based Policy Making. Canberra: Australian Government Productivity Commission, Commonwealth of Australia

Barnes TJ (2009) “Not only ... but also": Quantitative and critical geography. The Professional Geographer 61:292-300

Beaumont J, Loopmans M and Uitermark J (2005) Politicization of research and the relevance of geography: some experiences and reflections for an ongoing debate. Area 37: 118-126

Bell D (2007) Fade to grey: some reflections on policy and mundanity. Environment and Planning A 39: $541-554$

Blomley N (2007) Critical geography: anger and hope. Progress in Human Geography 31: 54-65

Blomley N (2008) The spaces of critical geography. Progress in Human Geography 32: 285-93

Brown M and Knopp L (2006) Places or polygon? governmentality, scale, and the Census in The gay and lesbian atlas. Population, Space and Place 12: 223-42

Castree N, Chatterton P, Heynen N, Larner W and Wright M (2010) Introduction: The point is to change it. Antipode 41: 1-9

Castree N (2000) Professionalisation, activism, and the university: whither 'critical geography'?' Environment and Planning A 32: 955-970

Chatteron P (2006,)'Give up activism' and change the world in unknown ways: or, learning to walk with others on uncommon ground. Antipode 38: 259-81.

Clark GL (1992) 'Real' regulation: the administrative state. Environment and Planning A 24: 615-627

Clark GL and Dear M (1984) State Apparatus: Structures and Language of Legitimacy. Boston: Allen and Unwin

Demerrit D (2005) The promises of collaborative research. Environment and Planning A 37: 20752082

Dunn C (2007) Participatory GIS - a people's GIS? Progress in Human Geography, 31, 616-637 
E Iwood S (2006) Critical issues in participatory IGS: Deconstructions, reconstructions, and new research directions. Transactions in GIS, 10, 693-708

Elwood S and Leitner H (2003) GIS and spatial knowledge production for neighborhood revitalisation: negotiating state priorities and neighborhood visions. Journal of Urban Affairs 25: 139-157

Ferguson J (2009) The uses of neoliberalism. Antipode 41: 166-184

Fuller D and Kitchin R (2004) Radical theory/critical praxis: academic geography beyond the academy. In D Fuller and R Kitchin (eds) Radical Theory/Critical Praxis: Making a Difference Beyond the Academy? (pp 1-20). Praxis (e)Press

Ghose R (2007) Politics of scale and networks of association in public participation GIS, Environment and Planning A, 39: 1961-1980

Gibson-Graham JK and O'Neill PM (2001) Exploring a new class politics of the enterprise. In JK Gibson-Graham, S Resnick and R Wolff (eds) Re/Presenting Class: Essays in Postmodern Marxism (pp 56-80). London: Duke University Press

Gibson-Graham JK (2006) Post-capitalist Politics. Minneapolis: University of Minnesota Press Giddens A (2006) Debating the Social Model: Thoughts and Suggestions. In P Diamond, M Ferrera, A Giddens , R, Liddle, J Palme, M Rodrigues, L Soete, L Tsoukalis, and P Weil, The Hampton Court Agenda: a Social Model for Europe. London: Policy Network, 95-150

Giddens A (2007a) New Labour: Tony Blair and after, British Politics, 2: 106-110

Giddens A (2007b) Over to you Mr Brown: How Labour Can Win Again, London: Polity Hanson-Thiem C (2010) Behind enemy lines: Reflections on the practice and production of oppositional research. Geoforum 41: 5-6

Harvey D (2006) The geographies of critical geography. Transactions of the Institute of British Geographers 31: 409-412

Healey P (2004) Creativity and urban governance. Policy Studies 25: 87-102

Healey P (2008) Knowledge flows, spatial strategy making, and the roles of academics. Environment and Planning C 26: 861-881 
Kitchin R and Dodge M (2007) Rethinking maps, Progress in Human Geography, 31: 331-344

Klodawsky F (2007) Choosing' participatory research: partnerships in space-time. Environment and Planning A 39: 2845-2860

Kobayashi A (1993) Representing ethnicity: political statistexts. Challenges of Measuring an Ethnic World: Science, Politics, and Reality (pp 513-525). Washington, DC: Statistics Canada and U.S. Bureau of the Census, U.S. Government Printing Office

Kuss M and Agnew J (2008) Theorizing the state geographical: sovereignty, subjectivity, territoriality, In K Cox, M Low and J Robinson J (eds) The Sage Handbook of Political Geography (pp 95-107). London: Sage

Kwan MP (2009) Critical quantitative geographies. Environment and Planning A 41: 261-264

Larner W, Le Heron R and Lewis N (2007) Co-constituting 'after neo-liberalism': political projects and globalizing governmentalities in Aotearoa, New Zealand. In K England and K Ward (eds) Neoliberalization: States, Networks, People (pp 223-247). Oxford: Blackwell

Le Heron R (2007) Globalisation, governance and post-structural political economy: perspectives from Australia. Asia Pacific Viewpoint 48: 26-40

Marcuse, P (2009) From critical urban theory to the right to the city. City 13: 185-97

Martin R (2001) Geography and Public Policy: the case of the missing agenda, Progress in Human Geography 25: 189-210

Massey D (2001) The Progress in Human Geography lecture: geography on the agenda. Progress in Human Geography 25: 5-17

Moss P (2004) A 'politics of local politics': praxis in places that matter. In D Fuller D and R Kitchin (eds) Radical Theory/Critical Praxis: Making a Difference Beyond the Academy? (pp103-15). Praxis (e)Press

Murphy A (2006) Enhancing geography's role in public debate. Annals of the Association of American Geographers 96: 1-13

O’Neill PM, and Moore N (2005) Real institutional responses to neoliberalism in Australia.

Geographical Research 43:19-28 
Offe C (1984) Contradictions of the Welfare State. London: Hutchinson

Offe C (1985) Disorganised Capitalism: Contemporary Transformations of Work and Politics. Cambridge: Polity Press

Olson E and Sayer A (2009) Radical geography and its critical standpoints: embracing the normative. Antipode 41: 180-198

Pain R (2006) Social geography: seven deadly myths in policy research. Progress in Human Geography 30: $250-259$

Painter J (2006) Prosaic geographies of stateness. Political Geography 25: 752-774.

Peck J (1999) Grey geography? Transactions of the Institute of British Geographers 24: 131-36

Peck J (2000) Jumping in, joining up and getting on. Transactions of the Institute of British Geographers 25: 255-258

Peck J, Theodore N and Brenner N (2010) Postneoliberalism and its malcontents. Antipode 94: 94-116 Poovey M (1998) The History of the Modern Fact: Problems of Knowledge in the Sciences of Wealth and Society. Chicago The University of Chicago Press.

Ramsey K (2009) A call for agonism: GIS and the politics of collaboration. Environment and Planning A 40: $2346-63$

Robertson M (2010) Performing environmental governance. Geoforum 41: 7-10

Routledge P (2004) Relational ethics of struggle. In D Fuller and R Kitchin (eds) Radical Theory/Critical Praxis: Making a Difference Beyond the Academy? (pp 79-91). Praxis (e)Press

Scott J (1998) Seeing Like a State. New Haven: Yale University Press

Smith N (2005) What's Left? Neo-critical geography, or the flat pluralist world of business class.

Antipode 37: 887-99

St Martin K (2009) Toward a cartography of the commons: Constituting the political and economic possibilities of place. The Professional Geographer 61: 1-15

Staheli L and Mitchell D (2005) The complex politics of relevance in geography. Annals of the Association of American Geographers 95: 357-372

Stevens A (2011) The use of evidence in policy-making in the UK, Journal of Social Policy, 40: 237-55 
Ward K (2005) Geography and public policy: a recent history of 'policy relevance'. Progress in Human Geography 29: 310-21

Whitehead M (2008) Cold monsters and ecological leviathans: Reflections on the relationships between states and the environment. Geography Compass 2: 414-432

Woods $\mathrm{M}$ et al , forthcoming, Applied policy research and critical human geography: some reflections on swimming in murky waters. Dialogues in Human Geography

Wyly E (2009) Strategic positivism. The Professional Geographer 61: 310-322 
Figure 1: Timeline of project collaboration with NSW state institutions

- Australian Research Council Linkage and UoN Collaborative Grants with NSW Dept of Housing (Hunter) (2001-2004)

- Australian Research Council Linkage and UoN Collaborative Grants with NSW Dept of Premiers and Regional Coordinators Management Group (Hunter): Families First (2003-2007)

- Australian Research Council Linkage Grant with NSW Dept of Premiers and Cabinet and Regional Managers Network (Hunter): Spatial Data Analysis Project (SDAP) (2007-2010)

- Development of the Research Agreement and Memorandum of Agreement (July-Dec 2007)

- Development of Memorandum of Agreement (Jan-June 2008)

- Meeting with NSW Privacy Commissioners Office

- Development with Crown Solicitors, RMN, University Solicitors

-Sign-off by NSW Privacy Commissioners Office

- Submission of Ethics Application and receipt of approval (Sept 2008)

- Meetings with SDAP Reference Committee and Agencies to workshop data suitability and availability (Sept 2008-Nov 2009)

- Development of Hunter Region Census Composite Indicator (Jan- March 2009)

- Presentation to Annual Planning Meeting of the Hunter RMN (April 2009)

- Agency data delivery, processing and analysis, development of SDAP Composite Indicators (Feb 2009-April 2010)

- SDAP Reference Committee Workshops (March-June 2010)

- Presentation to Annual Planning Meeting of the Hunter RMN (April 2010) 
i The academic research team brought together Pauline $M^{\complement} \subseteq$ Guirk (University of Newcastle) and Phillip O'Neill (University of Western Sydney) with other chief investigators Kathy Mee, Robert King and Lesley Instone (Newcastle) and research officers Karen Blackmore, Tanya Judd and Louise Askew (Newcastle) and Borce Dimeski (Western Sydney).

ii We engaged a critical GIS approach to deploy GIS' spatial science capacities within critical social theory, conscious of the social, political and epistemological implications of GIS' uncritical application (Kwan 2009). Our use is grounded, contextualized, reflexive and critical. Others have developed participatory GIS (PGIS) to pursue similar ends, as a collaborative critical practice of citizen engagement, especially via grass roots and marginalized groups, aimed to democratize access to spatial knowledge, diversify the forms of spatial knowledge represented and enhance the distribution of power in decision making (Elwood 2006). We see our collaborative deployment of GIS in more modest terms, though there are resonances. Our use is context- and issue- driven, it strives to incorporate and authorize local (though, in this case, practitioner) knowledge, its attention to the power of representation understands mapping as 'performance', and it pays explicit and critical attention to data composition as part of its remit of politicisation. These are all characteristic of PGIS (Dunn 2007). Yet our use does not engage with citizens and uses primarily conventional data forms sourced from state agency data holdings, although we were able to expand considerably the range of data used. We engage GIS analysis as a boundary object capable of creating points of commonality between us and our collaborators in the state, and, notably, between the various state agencies involved to build capacity and shape crossagency coalitions. GIS analysis created a field around which we could leverage critical practices for producing and informing texts and technologies through which state understandings, rationales and practices around social vulnerability could begin to be rewired and reworked.

iii The data provided for this project was primarily unit-record data at the level of the household. A key condition of the university ethics approval for the project, and of the approval from the NSW Privacy Commissioner for NSW state agencies to contribute data to the project, was that the data had to be aggregated to Collectors District (CD) level. CDs are geographical units used by the Australian Bureau of Statistics and are the smallest geographical area for which ABS data have been generally available publicly. iv Strict Australian privacy laws and an array of other institutional norms and practices have largely prevented interagency data sharing in Australia. So a paramount research issue for us became devising a framework to resolve constraints to data sharing while meeting legitimate expectations about data protection and observing legal regulation and ethics concerns. The researchers collaborated with the relevant RMN agencies, the Universities' solicitors, the NSW Crown Solicitor, and the NSW Privacy Commissioner to develop a suite of protocols and procedures which provide a robust framework enabling the secure, controlled and confidential sharing of data between agencies and the involvement of the academic researchers.

v The universities signed MoAs with the NSW Departments of Housing; Aging, Disability and Homecare; Education; Health, and Corrective Services; and the Police Force, Ambulance Service, and Fire Brigades.

vi Here we draw on Gibson-Graham's (2006) strategy of researching alongside rather than 'on' (for indeed 'for') other groups or organizations, maintaining the activities of social science research yet connecting to other knowledge producers. In our case, our coresearchers were government- rather than community-based. 
vii One illustration of these competing agenda is that some agencies readily provided data sets while others, particularly those whose operations had received high profile criticism or whose performance was politically sensitive, were slow to commit data into a context where they could not control its use and interpretation. Others withdrew from the project. Some were keen to have data incorporated which may have shed light on issues they had a particular concern with but which did not necessarily contribute well to the production of fine-scaled, spatially-sensitive metrics.

viii Critical, collaborative GIS was our technique of engagement here. It had its limitations when compared to the more practically radical PGIS. The lengthy, complex negotiations required to develop the project's enabling protocols and procedures are testament to how novel and untested the interagency sharing of data was in the NSW legal and institutional context. Extending these technologies to include citizen engagement in this project was not feasible. However, we did achieve a level of faith amongst agencies that data could be shared securely, and that indicators could be developed that were meaningfully fine-grained without breeching community concerns about confidentiality and privacy. And we embedded local practitioner knowledges within the project's indicators and within the practice of their use as diagnostic tools rather than ranking devices. We see these as offering incremental advances on setting institutional conditions under which new knowledge production practices, such as incorporating additional data sources able to more widely represent community needs and concerns, might flourish. We might hope that this is also an incremental advance on enabling citizen access to state spatial data and, ultimately, to greater involvement in decision-making and negotiation around public policy and program decisions. But we also note that caution is still needed here around the ambiguities and contradictions that persist in PGIS, often shadowing rather than displacing longstanding ontological, epistemological and socio-political critiques of GIScience (Dunn 2007, Ghose, 2007). 